\title{
Cameroon in the Whirlwind of the Millennium Development Goals
}

\section{KIJEM YUH Joseph}

\section{Joseph KIJEM YUH is a holder of a Postgraduate Diploma in Translation Studies and a}

Master's Degree in Human Rights Law and Humanitarian Law/Action. He is a Senior Translator at the Central Bureau for Censuses and Population Studies (BUCREP), Yaounde-

Cameroon.

Article No.: 081418115

Type: Short Comm.

DOI: 10.15580/GJSS.2018.3.081418115

Submitted: $14 / 08 / 2018$

Accepted: $24 / 08 / 2018$

Published: 25/09/2018

${ }^{*}$ Corresponding Author

Joseph KIJEM YUH

E-mail:yuh750@gmail.com

\section{Keywords:}

Poverty, Gender, Equality, Empowering, Women, Mortality, Maternal, Diseases, Sustainability, Partnership
This article is a summary attempt to examine the efforts or actions of the Cameroonian Government to attain the eight Millennium Development Goals. These goals were adopted by the Millennium Summit of 2000 within the confines of the Millennium Declaration. By 2015, they are supposed to be attained by all the countries which adopted them.

These goals are as follows: eradicating extreme poverty and hunger, achieving universal primary education, promoting gender equality and empowering women, reducing the child mortality rate, improving maternal health, combating HIV/AIDS, malaria and other diseases, ensuring environmental sustainability, and developing a global partnership for development.

Irrespective of the endeavours of the Cameroonian Government through its various structures (ministries, projects, etc) - to attain the said goals, much work is still needed in many aspects. To be more precise, the Cameroonian Government needs to work very hard, since, according to the 2008-2009 Human Development Report, Cameroon has made some improvements within the framework of only three of the said goals ( goals dealing with education and gender balance).

On the strength of the foregoing assertions, the Cameroonian Government should devise appropriate ways and means of remedying this undesirable or regrettable situation. The most important or significant of these ways and means is the setting up of a viable structure to coordinate and streamline Government action aimed at attaining the Millennium Development Goals, for purposes of speeding up the current moribund and disorganized machinery targeting the goals.

NB......It should be noted that this article was written during the MDGs period or era. 


\section{1) INTRODUCTION}

From time immemorial, mankind has been plagued by all sorts of predicaments or tribulations. This situation has plunged many countries and communities into agony or misery. To this effect, there have been so many attempts or endeavours to provide answers to the plight of these countries and communities. Some of these answers have been in the form of conventions, covenants, declarations, conferences, summits, etc. It was in this light that a historic summit took place in 2000 for purposes of fostering development in the world.

This summit is known as the Millennium Summit. It highlighted the Millennium Development Goals in the form of a declaration. This declaration was signed by many world leaders and international organizations. It is a blueprint as far as human rights or development issues are concerned. It goes a long way to portray the willingness of world leaders and international bodies to overcome the main human rights or development hurdles in an eight-goal approach.

The eight Millennium Development Goals tally with a broad spectrum of the rights enshrined in the Universal Declaration of Human Rights. These rights concern poverty, maternal health, education, gender equality, etc. In other words, the said goals are aimed at providing solutions to some rampant or common societal problems, problems which affect a very great part of the population of the world.

In Cameroon, a country in which the population of almost all the towns which had more than 50000 inhabitants each doubled from 1976 to $2005,{ }^{1}$ the Government is bound to take the Millennium Development Goals seriously. Are they really taken seriously? This is the question this article will set out to answer in a summary form. In other words, the efforts of the Cameroonian Government in implementing the said goals will be assessed in a synoptic manner from goal one to eight.

\section{2) GOAL ONE: ERADICATING EXTREME POVERTY AND HUNGER}

This goal is subdivided into three targets, namely,

1. Halving, between 1990 and 2015, the proportion of people whose income is less than one U.S. dollar a day per person;

2. Achieving full and productive employment as well as decent work for all, including women and young people;

3. Halving, between 1990 and 2015, the proportion of people who suffer from hunger.
What is the situation in Cameroon as far as these three targets are concerned?

As concerns the first target, the Cameroonian Government has been making some efforts to increase the income of Cameroonians so as to attain the said target. These efforts include the setting up of structures to alleviate extreme poverty (PIAASI for the informal sector, PAJER-U for projects dealing with youths, etc). However, much still has to be done. These structures, as most State institutions, are poorly managed. The funds needed to finance poverty alleviation projects are usually insignificant. Furthermore, since most Cameroonians of working age are in the informal sector, the Government is expected to set up a streamlined and wellfunded project for this sector to alleviate extreme poverty. Unfortunately, this is not the case due to the dismal situation in which PIAASI finds itself; so far, PIAASI has not been able to satisfy a good number of informal - sector actors.

Globally speaking, the state of poverty in Cameroon can be considered to be extreme. Poverty is present in almost all the sectors of life in Cameroon. In other words, many Cameroonians cannot afford adequate medical care, good food, good education, etc. Indeed, the poverty situation in Cameroon could be referred to as "severe and widespread". ${ }^{2}$ This situation went as far as provoking the 2008 hunger strikes. Since 2008, not much has been done to salvage the situation.

As regards the second target, the Cameroonian Government has taken some steps to provide full and productive employment as well as decent work to Cameroonians. An institution such as the National Employment Fund is ensuring, to some extent, that this target is attained. However, Government efforts are not enough because, at present, many young Cameroonians still remain unemployed or do not have full and productive employment because of a bad employment policy and a poor investment environment, an environment which is a scarecrow to potential foreign investors.

Moreover, most Cameroonian workers are informal - sector workers, a sector which, generally, in Cameroon, is allergic to decent work, etc. For instance, how can we be talking about decent work when the minimum salary in both the formal and informal sectors in Cameroon, according to the law, is roughly 28000 XAF? Furthermore, informal-sector workers do not have social - security benefits and a healthy working environment. Their work is not governed by the Labour Code!!! In a nutshell, an informal - sector worker in Cameroon does not have decent work, work that can provide for him:

"...the right to a standard of living adequate for the health and well-being of himself and of his family,

\footnotetext{
2 Pogge T., World Poverty and Human Rights,, Cambridge, Polity Press, 2008, p.2
}

\footnotetext{
1 Central Bureau for Censuses and Population Studies, Rapport de Présentation des Résultats Définitifs, Yaoundé, BUCREP, 2010, p. 20
} 
including food, clothing, housing and medical care and necessary services,..." ${ }^{3}$

Since most Cameroonian workers are employed by the informal sector, it could be concluded, on the basis of the aforementioned nature of this sector, that most Cameroonian workers do not have decent work or jobs.

The third and last target is also taken into consideration by the Cameroon Government through the institutions dealing with the said target. These institutions are mostly supervised by the Ministry of Agriculture and Rural Development. At present, the food situation in Cameroon cannot prompt anyone to talk of the presence of widespread extreme hunger though a few Cameroonians experience it. However, there are many Cameroonians, especially abandoned or street children as well as some inhabitants of the Far North Region, who cannot boast of food security since they eat irregularly. In the domain of the fight against extreme hunger, Cameroon should be yearning to get to the level of Ghana. Ghana has already met the target concerning extreme hunger greatly due to its stable good governance, sound macro-economic policies and increased agricultural investments. ${ }^{4}$

\section{3) GOAL TWO: ACHIEVING UNIVERSAL PRIMARY EDUCATION}

This goal has just one target, namely, the idea of ensuring that, by 2015, children everywhere, boys and girls alike, are able to complete a full course of primary education. Primary education is a very instrumental stage of any solid educational system. It is the elementary or rudimentary phase of a person's journey to the acquisition of a well- refined intellectual background. In fact, it is the starting point of a long and tedious race that can take any intellectually or academically ambitious individual to a very high level of both formal and informal education.

It was as a result of this primordial place of primary education in the educational, academic or intellectual domain that the United Nations, in the Universal Declaration of Human Rights, rendered it compulsory and free. Article 26 (1) of this declaration, which intends, inter alia, to enable children to complete a full primary education course, clearly states:

"Everyone has the right to education. Education shall be free, at least in the elementary and fundamental stages. Elementary education shall be compulsory..." 5

\footnotetext{
${ }^{3}$ Article 25(1) of the Universal Declaration of Human Rights (1948)

4 "Goal 1: Eradicate Extreme Poverty and Hunger" www.afdb.org/fileadmin/uploads/afdb/.../goal1_e ng.pdf (Consulted on 16/10/10)

${ }^{5}$ Article 26(1) of the Universal Declaration of Human Rights (1948)
}

Member countries of the United Nations have been endeavouring to implement the aforementioned portion of article 26 in varying degrees.

It was in this light that Cameroon, through its President, Paul Biya, officially stated that primary education would be free. This declaration of intention has, so far, been followed by very few substantial results. Apart from the fact that the Government is creating more primary schools ( some are created on paper), recruiting many more teachers, sensitizing parents to send their children to school, etc, much has not been done to ensure that primary education is free and compulsory (so as to ease the attainment of the above-mentioned target) since parents of primary school children still pay PTA levies ( in some cases, the amount is exorbitant ) while others provide the respective schools of their children with some items or tools.

Furthermore, despite an improvement (an indication of a change in the perception of educational issues) in the school attendance rate from 76.3 percent in the 1990s to 82.8 percent in 2009 in Cameroon (statistics culled or obtained from the 20082009 Human Development Report), ${ }^{6}$ some parents are still reluctant, unwilling or unable to send their offspring to school due to cultural, social, economic or financial reasons. Some withdraw their children from school especially because of the excessive demands or exigencies which are both in cash and in kind. In a nutshell, the Cameroonian Government still has to work very hard to enable a majority of Cameroonian children to complete their full primary education with some ease.

\section{4) GOAL THREE: PROMOTING GENDER EQUALITY AND EMPOWERING WOMEN}

This Goal has just one target, which is to eliminate gender disparity in primary and secondary education preferably by 2005 , and at all levels by 2015 . Gender inequality or disparity at the said level of education has been a Chinese puzzle. This problem has been managed in varying ways by the member countries of the United Nations. Indeed, it is a predicament whose solution can greatly improve the level of development in a country, especially a country like Cameroon which can make great use of the potentialities of educated women.

In Cameroon, gender equality in primary and secondary education is promoted through speeches, policies and actions. Though an increasing number of Cameroonian girls now go to school, ${ }^{7}$ there are still some girls whose parents do not see the need to send them to school. They prefer to see them in marital homes, even at very young ages. This phenomenon is rampant in some parts of the northern region of the country. Furthermore, proportionately, it is important to note that there are more female dropouts from the

\footnotetext{
6 Brenda Y., "Cameroon Achieves Mixed MDG Results", Cameroon Tribune, Yaounde, 22 September, 2010, p. 3.

${ }^{7}$ Ibid, p. 3.
} 
primary and secondary schools in Cameroon than male dropouts.

It is very difficult to sufficiently empower individuals who are either dropouts or illiterates. This is one of the hurdles the Government of Cameroon is experiencing in the case of women empowerment. In this connection, some Cameroonian women do not feel the need to be empowered by the State. Furthermore, the sensitization exercise to empower the said women is not taken very seriously by the Government, especially the Ministry of Women's Affairs and the Family though this ministry has set up some women empowerment centres in the country.

Thus, the Government has to make supplementary efforts in women empowerment. The recently adopted National Gender Policy is a step in the right direction. Cameroon's target should be the implementation of this policy so that, very soon, it may boast of having attained at least Rwanda's level of women empowerment and emancipation. It should be noted that Rwanda's women hold 56 percent of seats in Rwanda's Parliament, the highest percentage for women lawmakers in the world. ${ }^{8}$ The number of women in politics and decision-making in Rwanda has sharply increased.

\section{5) GOAL FOUR: REDUCING THE CHILD MORTALITY RATE}

The aforementioned goal has just one target, namely, the reduction by two -thirds, of the under-five mortality rate between 1990 and 2015. Child mortality or underfive mortality is a very serious health problem, especially in developing or third-world countries. This is due, inter alia, to the lack of some required medical equipment, the lack of enough financial means on the part of some parents of the children who need medical care, especially intensive or emergency medical care, the laxity and money-mindedness of some health workers as far as obstetric care is concerned, etc.

In Cameroon, the above-mentioned reasons for child mortality or under-five mortality are very noticeable in many cases despite Government efforts to curtail their presence. Furthermore, the Cameroonian health system is plagued by a high level of corruption, a contemptuous treatment reserved for health personnel especially junior or intermediate staff, the high prices of some drugs or medicines, etc. Taking cognizance of the foregoing,, the under-five mortality rate (that is, the probability that a newborn baby -per 1000 newborn babies - will die before the age of five), which is $131.1,9$ is quite high (2008 statistics). This rate is quite worrisome in a country which is counting very much on the younger generation.

\footnotetext{
8 "UNDP Rwanda - Millennium Development Goals" www.undp.org.rw/MDGs14.ht/m (Consulted on 14/10/10)

9 " Mortality Rate, Under 5, Cameroon" $14 / 10 / 10)$
}

\section{6) GOAL FIVE: IMPROVING MATERNAL HEALTH}

This goal comprises two targets, namely, the reduction, by three quarters, of the maternal mortality ratio between 1990 and 2015, and the acquisition of universal access to reproductive health by 2015 . Maternal health is a very important component of public health. If well handled, it can promote or protect the health of mothers and their babies, or, in other words, the health of a very significant segment of the population.

As concerns the first target, the Cameroonian Government, through some policies and actions, has been endeavouring to reduce the maternal mortality rate in the country. To this effect, there are health units and staff throughout the country who are catering for the health of mothers and their babies. However, Government efforts are not enough since maternal mortality remains very high in Cameroon; according to figures from the Health Ministry, the number of women who die while giving birth is estimated at 9000 per year. ${ }^{10}$

Furthermore, the maternal mortality situation in Cameroon since 1998 indicates an upward trend. Results from the Demographic and Health Surveys (DHS ) show that maternal mortality follows an evolutionary curve of about $2 \%$; it moved from 6000 deaths in 1998 to 7500 deaths in 2004 and 9000 deaths in 2010. This evolutionary or upward trend indicates that the Government has not been working very hard. In Cameroon, maternal deaths remain "common events". 11

As far as the second target is concerned, the situation is not very encouraging despite the goodwill of the Government in many domains. Reproductive health is still languishing in a miserable state. Some of the staff of many Government or State hospitals do not treat pregnant women fairly. Some of these women die under very cruel, inhuman or degrading circumstances and, by extension, in total violation of the basic right to life as enshrined in Article 3 of the Universal Declaration of Human Rights. ${ }^{12}$ This gruesome situation also contravenes Article 12 (1) of the International Covenant on Economic, Social and Cultural Rights which states as follows:

"The States Parties to the present Covenant recognize the right of everyone to the enjoyment of

\footnotetext{
10 "Over 9,000 Women Die Every Year in Cameroon During Child Birth"

www.afriqueavenir.org/.../2010/.../over-9000women-die-every-year-in-cameroon-during-child-birth (Consulted on 15/10/10)

${ }^{11}$ Cook R. and al, "Reproductive Health and Human Rights [Integrating Medicine, Ethics and Law]", New York, Oxford University Press Inc., 2003, p. 23

${ }^{12}$ Article 3 of the Universal Declaration of Human Rights (1948)
} 
the highest attainable standard of physical and mental health."13

In less unfortunate cases, many women seeking reproductive health are financially exploited and psychologically tortured. They experience hellish stages before they finally give birth to their babies. In a nutshell, they go through almost all the torments suffered by the other patients in need of health services.

\section{7) GOAL SIX: COMBATING HIV/AIDS, MALARIA AND OTHER DISEASES}

This goal is subdivided into three targets, namely, having halted the spread of HIV/AIDS by 2015 and begun reversing its spread; achieving, by 2010, the universal access to treatment for HIV/AIDS and in the case of those who need it; and having halted by 2015 and begun reversing the incidence of malaria and other major diseases.

In the case of the first target, the prevalence rate of HIV/AIDS is high in Cameroon. As of 2008, it stood at $5.1 \%$ in a population of about 18 million inhabitants; in other words, during the same year, over half a million people walked the streets carrying the HIV virus..... ${ }^{14}$. This high rate is partially due to insufficient or poor sensitization. Despite Government endeavours to sensitize Cameroonians through the activities of the Ministry of Health (precisely through the National AIDS Control Committee), it has not succeeded in devising adequate means enabling a substantial halt to the spread of HIV/AIDS. In this connection, the local AIDS Control Committees, whose creation was facilitated by the Government, have not succeeded in obtaining a breakthrough in sensitization.

The sensitization predicament is compounded by the presence of a disquieting rate of stigmatization. The Government has not sufficiently succeeded in warding off the stigmatization targeting HIV/AIDS patients. Thus, some of the individuals living with this illness are not willing to actively participate in the process concerning sensitization against the illness, thereby indirectly promoting its spread. This situation is partially due to the lack of protection of the rights of HIV/AIDS patients. At this level, the Government is not adequately implementing Guideline 11 of the International Guidelines on HIV/AIDS and Human Rights (2006 Consolidated Version) which stipulates as follows:

"States should ensure monitoring and enforcement mechanisms to guarantee the protection of HIV-

\footnotetext{
13 Article 26 of the International Covenant on Economic, Social and Cultural Rights (1966)

14 " High HIV/AIDS Prevalence in Africa (Cameroon as a Case Study) is due to Certain Cultural Habits" ezmearticles.com/?High-HIV-AIDS-Prevalence-in-Africa(Cameroon-As-a-Case-Study)-Is-Due-to-Certain-CulturalHabits\&id=4054001 (Consulted on 18/10/10)
}

related human rights, including those of people living with HIV, their families and communities." 15

This guideline is a very decisive stimulant to sensitization in AIDS - infested countries, especially in Cameroon.

The second target, which concerns the antiretroviral treatment of HIV/AIDS patients, is being taken into consideration by the Cameroonian Government. HIV/AIDS patients have access to antiretroviral drugs, though, at times, they may experience cases of shortage as it is the case with other drugs. The Government is endeavouring to make available antiretroviral treatment and drugs to those in need of them, though it still has to do a lot in order to water down the problem of intermittent shortages.

The third and ultimate target highlights the treatment of malaria and other major diseases. Malaria is a very deadly disease. Though the fight against it in Cameroon was intensified with the settingup of the National Programme for the Fight against Malaria, several studies indicate that this disease remains the leading cause of mortality and morbidity in Cameroon. ${ }^{16}$ Taking cognizance of this point, the greater attention paid by the Government to HIV/AIDS, when compared to the attention paid to malaria, is paradoxical and disturbing. To further corroborate this paradoxical and disturbing situation, it should be noted that a 2008 survey shows that $43 \%$ of deaths in Cameroon are malaria - related while $45 \%$ of cases of absence from work or school are due to malaria. Indeed, the Government has to work very hard to halt the prevalence or incidence of malaria in Cameroon.

Other major diseases, namely, epilepsy, sexually transmitted diseases except HIV/AIDS, cardio-vascular diseases, tuberculosis, etc. are also combated by the last and ultimate target of Goal Six. As far as Cameroon is concerned, I will highlight just one of these diseases, namely, tuberculosis. This disease is spreading in Cameroon despite the goodwill of the Government to fight against it (treatment of this disease is free and there is a National Tuberculosis Control Committee). It is spreading in prisons and some other centres which have poor hygienic conditions, especially among HIV/AIDS victims.

In a nutshell, Cameroon is fighting against the aforementioned major diseases in varying ways. It is benefiting from national and international assistance, especially through non-governmental bodies, UNAIDS, etc. It benefited from substantial funding from the Global Fund. It has been making use of its health staff throughout the country to halt the spread

\footnotetext{
15 International Guidelines on HIV/AIDS and Human Rights (2006 Consolidated Version)

16 Mimboé Prosper, "Cameroon: Situation of HIV/AIDS, Tuberculosis and Malaria", Tuesday, 11 May 2010, Cameroon,
}

africa.info.org/.../index.php?...cameroon...hivaidstuberculosis-malaria\&catid=37:health (Consulted on 18/10/10) 
of the said diseases. Unfortunately, it still has to work very hard to conquer them.

\section{8) GOAL SEVEN: ENSURING ENVIRONMENTAL SUSTAINABILITY}

This goal has four targets, namely, integrating the principles of sustainable development into country policies and programmes and reversing the loss of environmental resources; reducing biodiversity loss and achieving, by 2010, a significant reduction in the rate of loss; halving, by 2015, the proportion of people without sustainable access to safe drinking water and basic sanitation; and, lastly, having achieved, by 2020, a significant improvement in the lives of at least 100 million slum-dwellers.

The first target hinges on a very significant issue which is instrumental in the development programmes of countries, especially developing countries. This issue, which is sustainable development, refers to that sort of development which concerns current projects while, at the same time, taking care of, or envisaging the realization of, future projects [See Brundtland Report ("Our Common Future"), 1987]. In other words, the notion of sustainability in developmental issues targets development as far as both present and future cases, or short- and long-term cases, are concerned.

In Cameroon, sustainable development is experiencing a lot of problems irrespective of Government action in the domain. Many projects and programmes do not take into account future generations. They are managed as if there is no need for future considerations. These projects and programmes are found in the field of agriculture, labour, health, culture, mines, water resources, women empowerment, youth empowerment, etc. In a nutshell, they are cornered by a quagmire of very bad management and corruption.

The second target deals with the notion of biodiversity. This is another key issue, notion or term in the realm of development. It concerns the various components of nature or the environment (seas, rivers, oceans, forests, plants, etc). In Cameroon, notwithstanding the encouraging efforts of the Ministries of Environment and Nature Protection as well as that of Forestry and Wildlife, there are some very salient points which show that the ecological balance or the state of biodiversity in Cameroon is seriously threatened.The first point is overgrazing. Despite the haphazard nature of cattle grazing in the grazing lands of the country ( in the Adamawa Region, the North-West Region, etc), the Government, through the Ministry of Livestock, Fisheries and Animal Industries, is not making serious moves to curb the phenomenon, thereby threatening the existence or richness of the said lands. The second point is pollution. Though it is not yet a serious problem in Cameroon, the Government is not very present in this domain. The third problem is desertification. Cameroon does not have any concrete antidesertification policy. It has even gone as far as putting an abrupt end to the promising and highly- appreciated Green Revolution Operation which was meant to stop or curb the advancement of the desert towards the south of the country. The fourth point concerns protected animal species. They are seriously threatened and are in sore need of adequate protection. The fifth point deals with forests. They experience a situation similar to that of protected animal species. Lastly, there are many other points which indicate that the problem of biodiversity in Cameroon is worrisome and should be taken seriously.

The third target is a very crucial human-rights or life-saving pursuit. It brings into the limelight the issue of access to safe drinking water and basic sanitation. The two components involved, that is, safe drinking water and basic sanitation, are interwoven; activities in any of them could affect the other. The two components should be handled interdependently if any Government intends to adequately attain the aforementioned target.

As far as access to safe drinking water is concerned, in 2006, $70 \%$ of the population of Cameroon have access to safe drinking water. ${ }^{17}$ According to a $2008 \mathrm{WHO}$ /UNICEF Survey, the drinking water supply coverage in urban centres is $88 \%$ and $47 \%$ in rural areas. ${ }^{18}$ Despite these figures, many urban and rural areas do not have water supply networks, not to talk of reliable ones. The problem relating to drinking water supplied by the Government, through the Ministry of Energy and Water Resources, is being resolved at a very slow pace. Many households, even in very big towns such as Yaounde and Douala, experience serious water supply problems.

As regards the issue of sanitation coverage, the situation in the country is not good. According to the above-mentioned 2008 WHO/UNICEF Survey, in urban areas, only $58 \%$ of the population has access to improved sanitation facilities, while the rate in rural areas is $42 \% .^{19}$ Studies from various parts of the country indicate that many water resources used for household consumption are polluted at varying degrees because the waste disposal infrastructure is insufficient in urban areas. ${ }^{20}$ The sanitation situation is now worsening especially due to some cases of cholera in some regions of the country; some of these cases have claimed many lives especially in the northern regions.

The fourth target aims at significantly improving the lives of slum-dwellers. The problems of slum-dwellers in Cameroon, just like in many African countries, are acute. Even in big towns such as Douala, Yaounde, Bamenda, Nkongsamba, Garoua, Kumba, etc., slum-dwellers, who constitute the majority of the population in these towns, are living in

\footnotetext{
17 "Facing the Water Challenges in Cameroon: A WWWDR3 Case Study [Source: United Nations World Water Development Report (2009)]" waterwiki.net/.../Facing_the_Water_Challenges_in_Camer oon_A_WWWDR3_Case_Study- (15/10/10)

${ }^{18}$ Ibid

${ }^{19} \mathrm{Ibid}$

${ }^{20} \mathrm{Ibid}$
} 
abject poverty. Instead of designing poverty-alleviation policies, projects and programmes for these dwellers, some council or municipal authorities indulge in cruel, inhuman or degrading moves aimed at further frustrating them. To this effect, the unilateral decision taken by the Government Delegate of Yaounde to evict slum-dwellers from their neighbourhoods is a very good example; instead of providing these slumdwellers with means of livelihood, the said delegate has further pushed them into the world of misery and hardship. In a nutshell, the Government is not designing, or is unwilling to design, projects or programmes specifically or exclusively meant for slum-dwellers.

\section{9) GOAL EIGHT: DEVELOPING A GLOBAL PARTNERSHIP FOR DEVELOPMENT}

This goal concerns a collective move at the national and international level for purposes of development and the attainment of the other goals. The significance or importance of this goal was clearly spelt out by President Paul Biya during the 2010 Review Summit on the Millennium Development Goals in New York. It is subdivided into six targets.

The first target is an increased development of an open trading and financial system that is rulebased, predictable and non-discriminatory. It also includes a commitment to good governance, development and poverty reduction at the national and international level. The question at this level is - Is the Cameroonian Government committed to good governance, development and poverty alleviation? This commitment is mostly on paper, on the strength of the laxity in the fight against bad governance, especially corruption, as well as the level of enthusiasm to promote development and alleviate poverty. The hollow term "greater achievements "is quite illustrative since, almost seven years after the "re-election" of President Biya, very few great projects have been realized. To add insult to injury, the Government is now desperately or frantically in quest of funds (200 thousand million XAF), through treasury bonds, for the realization of great projects, after many years of conspicuous inactivity in the domain of great projects.

The second target is the attention that has to be paid to the special needs of the least developed countries. These include, inter alia, an enhanced programme of debt relief for heavily indebted poor countries, the cancellation of official bilateral debts and a more generous official development assistance for countries committed to poverty alleviation. Though the international community and bilateral partners of Cameroon have to increase their assistance to Cameroon in general, the Cameroonian Government has not been exemplary in the management of the Heavily Indebted Poor Countries' (HIPC) Funds, thereby slowing down the poverty-alleviation process.

The third target is the attention which has to be paid to the needs of landlocked countries and small -island developing States. This target does not concern Cameroon since it is neither a landlocked country nor a small island. However, there is need to disenclose the remote or landlocked regions of the country by linking them to the big towns and coastal region of the country through very good roads. At this level, a glaring and sorrowful case that has to be urgently addressed is that of Akwaya in the SouthWest Region.

The fourth target is the comprehensive attention that has to be paid to the debt problems of developing countries through national and international measures in order to render the debt burden sustainable in the long term. Though there is need to comprehensively tackle the debt burden in Cameroon, in particular, and in Africa, in general, Cameroon's debt and that of many other African countries are, currently, not sustainable since donors do not often take into consideration the genuine needs of the commonalty. This situation is exacerbated by the lack of solidarity of African leaders in the fight against the overburdening debts of Africa.

The fifth target concerns the access to affordable essential drugs in developing countries(in conjunction with the private sector). Cameroon has a structure (CENAME) which is responsible for the provision of essential drugs. The services provided by this structure are commendable to some extent. However, there is a sore need for a solid partnership between this structure and the private sector so as to broaden the distribution network of the said structure and, by extension, satisfy as many patients as possible throughout the country.

The sixth and last target is making available the benefits of new technologies, especially information and communication benefits (in conjunction with the private sector). The Government has made some strides in the provision of information and communication technology. There are some multimedia or information and communication centres in the country. Moreover, there is a National Agency for Information and Communication Technology (ANTIC). Nevertheless, the Government has to extend this technology to the entire country, especially areas which do not have access to electricity.

This summary assessment of Goal Eight in Cameroon is lopsided since it deals mainly with Cameroon and slightly or indirectly assesses the role or action of the international community and the private sector. It should be noted that the international community and the private sector have to play a great role for the attainment of this goal. This could be effectively done if there is an effective cooperation between the powers that be in Yaounde and the international community, especially in the domain of good governance. This assertion is in line with a statement made by the Foreign Affairs Minister of Mauritius (Hon. Arrin Boolell) during the 2010 MDGs Summit. He said that the destinies of developing and developed countries were inextricably linked. ${ }^{21}$

\footnotetext{
${ }^{21}$ Shey P., "Striking Declarations by World Leaders at the MDGs Summit," Cameroon Tribune, Yaounde, 23 September, 2010, p. 3
} 
Furthermore, he insisted on the need for an effective cooperation among the nations of the world. ${ }^{22}$

\section{0) CONCLUSION}

The attainment of the Millennium Development Goals in Cameroon is really in a whirlwind. In other words, the Government has to carry out and implement some reforms to improve its poor MDGs track record. This is simply due to the fact that Cameroon is lagging behind in many aspects as far as the realization or attainment of the said goals is concerned, as shown by the 20082009 Human Development Report which states that progress has been obtained as regards only three out of the eight goals; two out of these three goals concern education and gender balance. ${ }^{23}$

The most important reform is the setting -up of a well organized structure or institution to coordinate and promote Government action geared to the attainment of the goals. This structure should be able to streamline or coordinate the action of all the ministries involved in the attainment of these goals. This will be an opportunity to re-energize the global commitment expressed through the Millennium Declaration in 2000 by world leaders to attain the eight development goals. ${ }^{24}$ The said structure should also be able to ease the obtainment of the needed funds and thoroughly supervise their use. Furthermore, it should make good use of the fourteen thematic analyses or reports of the 2005 General Population and Housing Census so as to better understand and master the needs of Cameroonians as far as the Millennium Goals are concerned. ${ }^{25}$ These thematic analyses or reports concern human rights issues such as the socio-economic situation of the physically challenged, elderly persons, women, youths and children. Lastly, the structure that will be set up should be able to convince the Head of State and his Government to get closer to the people, through a sustainable and meticulous decentralization scheme, so as to better grasp and overcome popular worries or concerns relating to the said goals, especially the worries concerning poverty and hunger because a hungry man is an angry man.

For the said structure to be sustainable, credible and viable, there should be a tripartite consultation process leading to its setting- up. The stakeholders of this tripartite dispensation are the Government, political parties and the civil society.

\section{BIBLIOGRAPHY}

\footnotetext{
22 Ibid

${ }^{23}$ Brenda Y., "Cameroon Achieves Mixed MDG Results", Cameroon Tribune, Yaounde, 22 September, 2010, p. 3.

${ }^{24}$ Mbela G., "World Bank Demands More Investments in Developing Countries", Cameroon Tribune, Yaounde, 22 September, 2010, p. 9

25 The Fourteen Thematic Analyses or Reports of the 2005 General Population and Housing Census
}

\section{A) Books}

1) Cook, R. and al, "Reproductive Health and Human Rights [Integrating Medicine, Ethics and Law]", New York, Oxford University Press Inc.,2003

2) Central Bureau for Censuses and Population C Studies, Rapport de Présentation des Résultats Définitifs, Yaounde, BUCREP, 2010

3) Pogge T., World Poverty and Human Rights, Cambridge, Polity Press, 2008

\section{B) Articles}

1) Brenda, Y., "Cameroon Achieves Mixed MDG Results", Cameroon Tribune, Yaounde, 22 September, 2010

2) "Goal 1: Eradicate Extreme Poverty and Hunger" www.afdb.org/fileadmin/uploads/afdb/.../goal1_en g.pdf (Consulted on 16/10/10)

3) "Cameroon: Situation of HIV/AIDS, Tuberculosis and Malaria", africa.info.org/.../index.php?...cameroon...hivaidstuberculosis-malaria\&catid=37:health (Consulted on $18 / 10 / 10$ )

4) "Facing the Water Challenges in Cameroon: $A$ WWWDR3 Case Study [Source: United Nations World Water Development Report (2009)]" waterwiki.net/.../Facing_the_Water_Challenges_i n_Cameroon_A_WWWDR3_Case_Study(Consulted on 15/10/10)

5) "High HIV/AIDS Prevalence in Africa (Cameroon as a Case Study) is due to Certain Cultural Habits" ezmearticles.com/?High-HIV-AIDSPrevalence-in-Africa-(Cameroon-As-a-CaseStudy)-Is-Due-to-Certain-CulturalHabits\&id=4054001 (Consulted on 18/10/10)

6) Mbela, G., "World Bank Demands More Investments in Developing Countries", Cameroon Tribune, Yaounde, 22 September, 2010

7) " Mortality Rate, Under 5, Cameroon" www.google.com.publicdata (Consulted on $14 / 10 / 10)$

8) "Over 9,000 Women Die Every Year in Cameroon During Child Birth" www.afriqueavenir.org/.../2010/.../over-9000women-die-every-year-in-cameroon-during-childbirth (Consulted on 15/10/10)

4) Shey, P., "Striking Declarations by World Leaders at the MDGs Summit", Cameroon Tribune, Yaounde, 23 September, 2010.

9) "UNDP Rwanda - Millennium Development Goals" www.undp.org.rw/MDGs14.htlm (Consulted on 14/10/10)

\section{C) Legal Instruments}


1) International Covenant on Economic, Social and Cultural Rights (1966)

2) Universal Declaration of Human Rights (1948)
1) International Guidelines on HIV/AIDS and Human Rights (2006 Consolidated Version)

2) The Fourteen Thematic Analyses or Reports of the 2005 General Population and Housing Census

\section{D) Other Materials}

Cite this Article: KIJEM YUH J (2018). Cameroon in the Whirlwind of the Millennium Development Goals. Greener Journal of Social Sciences, 8(3): 029-037, http://doi.org/10.15580/GJSS.2018.3.081418115. 